\title{
MEIOS DE CULTURA NO DESENVOLVIMENTO DE ÁPICES CAULINARES DE MAMONEIRA (Ricinus communis $\mathrm{L}$.) in vitro
}

\author{
Culture media on in vitro development of castor bean (Ricinus communis L.) stem tips
}

\author{
Fernanda Bertozzo 1 , Isaac Stringueta Machado ${ }^{2}$
}

\begin{abstract}
RESUMO
A pesquisa da composição do meio de cultura mais adequado à espécie vegetal e ao tipo de explante empregado é o fator de maior relevância da cultura de tecidos. O cultivo de ápice caulinar com recuperação da planta matriz é uma técnica de grande impacto para a propagação de plantas in vitro, regeneração de plantas livres de vírus, conservação de germoplasma e modificação genética. Objetivou-se, neste trabalho, avaliar composições do meio de cultivo para organogênese direta in vitro a partir de ápices caulinares pertencentes à população FCA-UNESP-PB de mamoneira (Ricinus communis L.), com vistas à propagação clonal de genótipos elite. Foram testadas quatro formulações: MS básico (T1), MS modificado 1 (T2), MS modificado 2 (T3) e WPM (T4), em delineamento experimental inteiramente casualizado, com 20 repetições em cada tratamento, sendo a repetição 1 ápice caulinar/frasco. O T3 apresentou-se superior e diferiu significativamente dos outros tratamentos apresentando $35 \%$ dos ápices caulinares diferenciados e desenvolvidos; seguiu-se o T2 com 10\% e os tratamentos T1 e T4 não apresentaram diferenciação de tecidos. Os resultados permitiram concluir que os balanceamentos de sais minerais nos meios de cultura avaliados, especialmente a relação $\mathrm{NO}_{3} / \mathrm{NH}_{4} \mathrm{e}$ ausência de $\mathrm{FeSO}_{4} \cdot 7 \mathrm{H}_{2} \mathrm{O}$, indicaram grande influência no desenvolvimento de ápices caulinares de mamoneira.
\end{abstract}

Termos para indexação: Ápices caulinares, cultura de tecidos, organogênese direta.

\section{ABSTRACT}

The research of the culture medium composition suitable for plant species and the type of explant to be used is the most significant factor in plant tissue culture. The culture of stem tips with plant donor recovery is a technique of great impact for the in vitro plant production, regeneration of virus-free plants, germoplasm conservation and genetic modification. The objective of this study was to evaluate culture media composition in vitro on direct organogenesis of the FCA-UNESP-PB population of castor bean (Ricinus communis L.), from stem tips for clonal propagation of elite genotypes. Four formulations were tested: basic MS (T1), modified MS 1 (T2), modified MS 2 (T3) and WPM (T4) in a completely randomized experimental design with 20 replicates pertreatment with 1stem tip/flask. The treatment T3was superior, and differed significantly from the other treatments, with $35 \%$ of stem tips developed, followed by $10 \%$ in T2. T1 and T4 showed no plant tissue differentiation. The results allowed to conclude that the balance of mineral salts and culture media evaluated especially the rate $\mathrm{NO}_{3} / \mathrm{NH}_{4}$ and the absence of $\mathrm{FeSO}_{4} .7 \mathrm{H}_{2} \mathrm{O}$ showed nigh influence on the development of stem tips of castor bean.

Index terms: Stem tips, plant tissue culture, direct organogenesis.

(Recebido em 17 de junho de 2009 e aprovado em 10 de março de 2010)

\section{INTRODUÇÃO}

A planta Ricinus communis L. pertence à família Euphorbiaceae, que possui cerca de 290 gêneros e aproximadamente 7.500 espécies (Angely, 1970; Joly, 1979; Barroso, 1986). Aclimatou-se às condições edafoclimáticas brasileiras sendo encontrada em, praticamente, todas as regiões. O processamento de suas sementes dá origem ao óleo e à torta. Seu cultivo apresenta importância socioeconômica crescente, pois o óleo extraído de suas sementes presta-se a uma ampla gama de setores da indústria. Representa hoje, devido às suas características físicoquímicas, uma das alternativas para produção de biodiesel; podendo ser utilizada ainda, como matéria-prima da indústria de fármacos, biopolímeros e outros. Além disso, a haste da mamoneira pode servir como fornecedora de celulose própria para a fabricação de papel (Azzini et al., 1984). A torta, subproduto da extração do óleo das sementes, é um adubo orgânico de elevado valor econômico, além de apresentar propriedades nematicidas (Akhtar \& Mahmood, 1996) e inseticidas (Carlini \& Sá, 2002).

No Brasil, existem programas que têm como base o melhoramento genético da mamoneira. Um dos objetivos desses programas é a produção de híbridos comerciais. Entre as etapas iniciais desse processo está a obtenção de linhagens pistiladas, ou seja, plantas que possuem racemos com $100 \%$ de flores femininas. O grande entrave do desenvolvimento dessas plantas é que as mesmas não

${ }^{1}$ Universidade Estadual Paulista - Faculdade de Ciências Agronômicas - Campus Botucatu - Rua José Barbosa de Barros, 1780 - Cx. P. 237 - 18610 -307 Botucatu, SP - fbertozzo@yahoo.com.br

'Universidade Estadual Paulista - Faculdade de Ciências Agronômicas - Campus Botucatu - Botucatu, SP 
podem ser autofecundadas, já que não possuem flores masculinas em seus racemos; então surge a necessidade do cruzamento com plantas monóicas para que se dê continuidade ao processo de reprodução. Nesse momento, perde-se a pureza genética das plantas devido ao cruzamento com plantas monóicas. Surge então a necessidade de um método eficaz de propagação assexuada no qual a pureza genética seja mantida juntamente com a produção de clones.

A micropropagação possibilita a multiplicação por via assexuada resultando em um grande número de descendentes. Genótipos superiores podem ser multiplicados sem modificação em sua estrutura genética, fato que é de extrema importância para manutenção de características desejadas conseguidas através de um programa de melhoramento. Possibilita ainda, proporcionar maior precocidade na produção e abreviar o tempo necessário à liberação de uma nova cultivar (Bueno et al., 2006).

A organogênese é o processo de neoformação de parte aérea ou raiz a partir de calo ou de outros explantes (Torres et al., 2000). De acordo com Peres (2002), a organogênese in vitro pode ser dividida em dois processos distintos, a organogênese direta quando o explante já possui células meristemáticas, e a organogênese indireta quando há a necessidade de desdiferenciação do explante, com a consequente formação de calo antes do estabelecimento das células competentes.

Das técnicas da propagação in vitro, a cultura de ápices caulinares pode ser usada na produção de plantas, limpeza clonal, conservação e intercâmbio de germoplasma e transformação (Torres et al., 1998).

O grande obstáculo desse método biotecnológico é o ajuste de um protocolo com um meio de cultivo que supra as necessidades da planta tornando-a propícia à multiplicação em larga escala. Cada espécie de planta requer um meio de cultura específico para ter um desenvolvimento considerado normal, por isso, torna-se fundamental o estudo da composição em sais minerais, suplementos orgânicos e o balanceamento e tipo de reguladores vegetais para a indução da diferenciação da parte aérea ou raiz das plantas (Santos et al., 2005).

O meio MS (Murashige \& Skoog, 1962) formulado para o cultivo in vitro de células de tabaco (Nicotiana $\mathrm{sp}$ ), apresentou-se eficiente para a maioria das espécies vegetais herbáceas; no entanto, as espécies mais lenhosas frequentemente não são responsivas à composição original. No cultivo dessas espécies, modificações como a redução do teor de macronutrientes, apresentam melhor desempenho. Outra possibilidade é a substituição do meio MS basal pelo meio WPM (Lloyd \& McCown, 1980), de composição mais diluída em nutrientes e originalmente formulado para espécies lenhosas (Melo et al., 1999).). De acordo com Pasqual (2001) citado por Soares et al. (2009), o meio WPM possui $25 \%$ das concentrações de íons nitrato e amônia quando comparado ao meio MS, no entanto, apresenta mais potássio e um elevado nível de íons sulfato.

Objetivou-se, neste trabalho avaliar o efeito de diferentes meios de cultura na diferenciação in vitro de ápices caulinares em partes aéreas de plantas de mamoneira, pertencentes à população FCA-UNESP-PB (porte baixo), livres de contaminações e de oxidação fenólica.

\section{MATERIAL E MÉTODOS}

O experimento foi conduzido no Laboratório de Biotecnologia Ambiental, do Departamento de Recursos Naturais, da Faculdade de Ciências Agronômicas - UNESP, Botucatu/SP.

Os meios nutritivos testados foram: MS basal (T1); MS modificado 1 (T2); MS modificado 2 (T3) e WPM (T4), cujas formulações e suplementações são apresentadas na Tabela 1. O pH dos meios foi aferido em 5,8 antes da adição do ágar. Os meios foram distribuídos em alíquotas de $5 \mathrm{ml}$ por tubo de ensaio e esterilizados a $121^{\circ} \mathrm{C}$, sob pressão de 1 atm, durante 20 minutos.

Ápices caulinares de mamoneira foram excisados de plantas matrizes de seis meses de idade, da população FCA-UNESP-PB, provenientes de um programa de melhoramento genético da FCA-UNESP. Os explantes foram lavados em água corrente por 12 horas e imersos por 12 horas sob agitação constante, em solução contendo o fungicida benomil a $0,5 \mathrm{~g} \mathrm{~L}^{-1} \mathrm{e}$ o antibiótico cloranfenicol na mesma concentração.

Procedeu-se à desinfestação superficial dos explantes com etanol $70 \%$ por 1 minuto, seguido de solução de hipoclorito de sódio a $2 \%$ de cloro ativo e Tween $20^{\circledR}$ ( 1 gota $100 \mathrm{ml}^{-1}$ de hipoclorito de sódio) por 20 minutos, e 5 lavagens com água deionizada estéril. Em câmara de fluxo laminar, os ápices caulinares foram transferidos para os diferentes tratamentos.

Após a inoculação dos explantes, os frascos foram incubados em câmara de germinação (B.O.D.) em condições de escuro e temperatura de $26^{\circ} \mathrm{C} \pm 2^{\circ} \mathrm{C}$; após 7 dias foram submetidos a fotoperíodo de $16 \mathrm{~h}$ de luz/8h de escuro e intensidade luminosa de 1000 lux.

$\mathrm{O}$ delineamento experimental foi o inteiramente casualizado, com 4 tratamentos e 20 repetições em cada tratamento sendo a repetição constituída por 1 ápice caulinar/ frasco. Os experimentos foram avaliados 30 dias após a inoculação. A variável observada foi a ocorrência, ou não, da diferenciação dos ápices caulinares por meio do alongamento do sistema caulinar e desenvolvimento foliar. 
Para a análise estatística dos resultados, os dados coletados em porcentagem foram transformados para arco seno $(\sqrt{x+0,5} / 100)$, visando à análise da variância. Compararam-se as médias dos tratamentos pelo teste de Tukey, a 5\% de probabilidade.

\section{RESULTADOS E DISCUSSÃO}

A análise estatística dos dados revelou diferenças significativas entre os tratamentos para a variável diferenciação em partes aéreas dos ápices caulinares, com o meio MS modificado 2 (T3) apresentando o maior número de ápices caulinares diferenciados em partes aéreas. Os demais tratamentos não apresentaram diferenças significativas entre si.

Os resultados das avaliações obtidos 30 dias após a inoculação podem ser observados na Figura 1, que relaciona a frequência de diferenciação dos ápices caulinares em parte aérea de mamoneira, cultivados em diferentes meios de cultura. Observa-se que no T3, 35\% das 20 repetições testadas apresentaram diferenciação em estruturas caulinar e foliar.

Como já descrito, os meios MS básico (T1) e WPM (T4) não induziram a diferenciação dos ápices caulinares. Resultados discordantes foram obtidos por Melo et al.

Tabela 1 - Composição dos meios MS básico, MS modificado 1, MS modificado 2 e WPM.

\begin{tabular}{|c|c|c|c|c|}
\hline Componentes & $\begin{array}{c}\text { MS } \\
\text { Básico } \\
\text { mg L }^{-1}+ \\
\text { suplementações }\end{array}$ & $\begin{array}{c}\text { MS } \\
\text { Modificado } 1 \\
\text { mg L L }^{-1}+ \\
\text { suplementações }\end{array}$ & $\begin{array}{c}\text { MS } \\
\text { Modificado } 2 \\
\text { mg L }^{-1}+ \\
\text { suplementações }\end{array}$ & $\begin{array}{c}\text { WPM } \\
\text { Básico } \\
\mathrm{mg} \mathrm{L}^{-1}+ \\
\text { suplementações }\end{array}$ \\
\hline $\mathrm{NH}_{4} \mathrm{NO}_{3}$ & 1650 & 1650 & 825 & 400 \\
\hline $\mathrm{KNO}_{3}$ & 1900 & 1900 & 950 & - \\
\hline $\mathrm{H}_{3} \mathrm{BO}_{3}$ & 6,2 & 6,2 & 6,2 & 6,2 \\
\hline $\mathrm{KH}_{2} \mathrm{PO}_{4}$ & 170 & 170 & 170 & 170 \\
\hline $\mathrm{K}_{2} \mathrm{SO}_{4}$ & - & - & - & 990 \\
\hline $\mathrm{Ca}\left(\mathrm{NO}_{3}\right)_{2} 4 \mathrm{H}_{2} \mathrm{O}$ & - & - & - & 556 \\
\hline $\mathrm{KI}$ & 0,83 & 0,83 & 0,83 & - \\
\hline $\mathrm{Na}_{2} \mathrm{MoO}_{4} 2 \mathrm{H}_{2} \mathrm{O}$ & 0,25 & 0,25 & 0,25 & 0,25 \\
\hline $\mathrm{CoCl}_{2} 6 \mathrm{H}_{2} \mathrm{O}$ & 0,025 & 0,025 & 0,025 & - \\
\hline $\mathrm{CaCl}_{2} 2 \mathrm{H}_{2} \mathrm{O}$ & 440 & 440 & 440 & 96 \\
\hline $\mathrm{MgSO}_{4} 7 \mathrm{H}_{2} \mathrm{O}$ & 370 & 370 & 370 & 370 \\
\hline $\mathrm{MnSO}_{4} \mathrm{H}_{2} \mathrm{O}$ & - & - & - & 22,3 \\
\hline $\mathrm{MnSO}_{4} 4 \mathrm{H}_{2} \mathrm{O}$ & 22,3 & 22,3 & 22,3 & - \\
\hline $\mathrm{ZnSO}_{4} 7 \mathrm{H}_{2} \mathrm{O}$ & 8,6 & 8,6 & 8,6 & 8,6 \\
\hline $\mathrm{CuSO}_{4} 5 \mathrm{H}_{2} \mathrm{O}$ & 0,025 & 0,025 & 0,025 & 0,25 \\
\hline $\mathrm{Na}_{2} \mathrm{EDTA}_{2} \mathrm{H}_{2} \mathrm{O}$ & 37,3 & 37,3 & 37,3 & 37,3 \\
\hline $\mathrm{FeSO}_{4} 7 \mathrm{H}_{2} \mathrm{O}$ & 27,8 & 27,8 & - & 27,8 \\
\hline Tiamina $\mathrm{HCl}$ & 0,1 & 0,1 & 0,1 & 1,0 \\
\hline Ác. nicotínico & 0,5 & 0,5 & 0,5 & 0,5 \\
\hline Piridoxina $\mathrm{HCl}$ & 0,5 & 0,5 & 0,5 & 0,5 \\
\hline Glicina & 2,0 & 2,0 & 2,0 & 2,0 \\
\hline Inositol & 100,0 & 100,0 & 100,0 & 100,0 \\
\hline Sacarose & 30000 & 30000 & 15000 & 30000 \\
\hline PVP & 250 & 250 & 250 & 250 \\
\hline Carvão Ativado & - & 1000 & 1000 & 1000 \\
\hline Benomil & - & 1000 & 1000 & 1000 \\
\hline Ágar & 7000 & 7000 & 3500 & 7000 \\
\hline
\end{tabular}


(1999), que testaram outra forma de explante, os segmentos nodais de aceroleira (Malpighia emarginata DC.), em diferentes composições de meio (MS, DKW e WPM) e chegaram à conclusão de que o meio WPM favoreceu, além da diferenciação dos explantes, a indução da multiplicação de brotações. Também Ribeiro et al. (2002) trabalhando com café (Coffea arabica L.), ao inocularem segmentos nodais de $2 \mathrm{~cm}$ de comprimento em diferentes meios de cultura (MS basal, Knudson, WPM e White), obtiveram melhores resultados com os meios WPM e MS basal.

Resultados semelhantes aos aqui encontrados foram obtidos por Machado et al. (2007) ao avaliarem o efeito dos meios de cultura MS/2, NN, WPM, QL e $\mathrm{C}_{2} \mathrm{D}$ no cultivo de segmentos nodais do porta-enxerto de videira "VR043-043". Também Gray \& Benton (1990) testaram o meio WPM no desenvolvimento de meristemas apicais de uva (Vitis rotundifolia Michx.) e obtiveram resultados negativos. Ainda, no trabalho de Oliveira et al. (2000), foi testada, em meio MS, a diferenciação de meristemas apicais de diferentes variedades de mandioca (Manihot esculenta Crantz) medindo entre 0,4 a $0,6 \mathrm{~mm}$; como resultados foram alcançados níveis satisfatórios no estabelecimento e multiplicação dos explantes. Empregando o meio MS e o WPM no cultivo in vitro de amoreira-preta "Xavante" e framboeseira "Batum" e "Heritage", Leitzke et al. (2010), encontraram os melhores resultados utilizando o meio MS para ambas as espécies.

As modificações que revelaram o tratamento mais eficiente deste trabalho são compatíveis com as descritas por Teixeira (2001), que relatou, para o controle da oxidação fenólica e diferenciação de tecidos, a eficácia da redução em $50 \%$ da concentração original dos macronutrientes $\mathrm{NH}_{4} \mathrm{NO}_{3}$ e $\mathrm{KNO}_{3}$, da sacarose e do ágar do meio MS. Ademais, a ausência do $\mathrm{FeSO}_{4} \cdot 7 \mathrm{H}_{2} \mathrm{O}$ no meio de cultivo pode ter contribuído para o melhor resultado, pois o mesmo está relacionado com a oxidação dos tecidos; observação também encontrada por Barghchi \& Alderson (1983), na propagação in vitro de Pistacia spp.

Mesmo com todos os procedimentos preventivos empregados neste trabalho, a oxidação fenólica apresentouse renitente em todos os tratamentos, além de significativa contaminação microbiana. Essas limitações, comuns na cultura de tecidos de plantas da família Euphorbiaceae, são previsíveis e permanecem de difícil controle. De acordo com Reddy \& Bir Bahadur (1989) e Molina \& Schobert (1995), as tentativas de modificar ou aperfeiçoar características em Ricinus usando técnicas de cultura de tecidos são raras devido ao fato de essa ser uma espécie recalcitrante, apresentando assim grande dificuldade na regeneração in vitro. A contaminação é mais frequente em explantes advindos de plantas cultivadas em campo, como no presente trabalho, e esse também é considerado um grande obstáculo para o estabelecimento de muitas espécies in vitro. De acordo com observações de Litz \& Conover (1978), quando os explantes são retirados de plantas cultivadas em campo e introduzidos in vitro, a taxa de contaminação microbiana pode chegar a 95\%, mesmo após a descontaminação.

Com base nos resultados aqui divulgados, observa-se que são necessários mais estudos e pesquisas

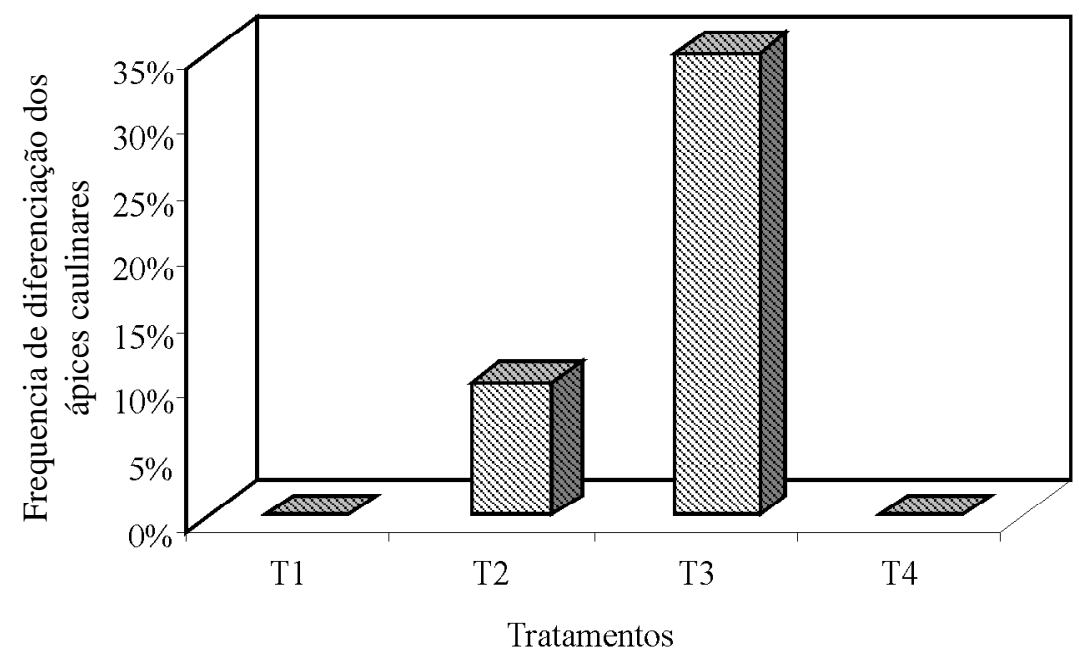

Figura 1 - Diferenciação de ápices caulinares de mamoneira em parte aérea pela organogênese direta, em diferentes composições de meios de cultura (MS básico (T1), MS modificado 1 (T2), MS modificado 2 (T3), WPM (T4)). 
na área de cultivo de ápices caulinares de mamoneira, tanto em relação ao desenvolvimento da parte aérea, que foi visto neste trabalho, quanto à indução de sistema radicular, além da multiplicação de brotações.

\section{CONCLUSÕES}

A redução de $\mathrm{NH}_{4} \mathrm{NO}_{3}$ e $\mathrm{KNO}_{3}$, sacarose e ágar em $50 \%$ da concentração do meio MS basal, ausência de $\mathrm{FeSO}_{4} \cdot 7 \mathrm{H}_{2} \mathrm{O}$, suplementação com os agentes antioxidantes polivinilpirrolidona (PVP) e carvão ativado e , ainda, adição do fungicida benomil ao meio de cultivo foi o mais eficiente para o estabelecimento e a indução da diferenciação e desenvolvimento de ápices caulinares de mamoneira, em partes aéreas, por meio da organogênese direta.

\section{REFERÊNCIAS BIBLIOGRÁFICAS}

AKHTAR, M.; MAHMOOD, I. Control of plant-parasitic nematodes with organic and inorganic amendments in agricultural soil. Applied Soil Ecology, Aligarh, v.4, n.3, p.243-247, Nov. 1996.

ANGELY, J. Flora analítica e fitográfica do Estado de São Paulo. São Paulo: Ayrton, 1970. 330p.

AZZINI, A.; SAVY FILHO, A.; SALGADO, A.L. de B.; ARNALDI, F.Z. Deslignificação dos resíduos agrícolas da cultura da mamona para produção de celulose e papel. Bragantia, Campinas, v.43, n.2, p.519-530, 1984.

BARGHCHI, M.; ALDERSON, P.G. In vitro propagation of Pistacia species. Acta Horticulturae, Amsterdam, v.131, p.49-60, 1983.

BARROSO, G.M. Sistemática de angiospermas do Brasil. Viçosa, MG: UFV, 1986. 3p.

BUENO, L.C. de S.; MENDES, A.N.G.; CARVALHO, S.P. Melhoramento genético de plantas: princípios e procedimentos. 2.ed. Lavras: UFLA, 2006. 319p.

CARLINI, C.R.; SÁ, M.F.G. Plant toxic proteins with inseticidal properties: a review on their potentialities as bioinseticides. Toxicon, v.40, p.1515-1539, 2002.

GRAY, D.J.; BENTON, C.M. Micropropagation and plant establishment of Muscadine grape. Proceedings of

Florida State Horticultural Society, Hruter Haven, v.103, p.300-302, 1990.
JOLY, A.B. Botânica econômica: as principais culturas brasileiras. Brasília: Hucitec, 1979. 66p.

LEITZKE, L.N.; DAMIANI, C.R.; SCHUCH, M.W. Influência do meio de cultura, tipo e concentração de citocininas na multiplicação in vitro de amoreira-preta e framboeseira. Ciência e Agrotecnologia, Lavras, v.34, n.2, p.352-360, mar./abr. 2010.

LITZ, R.E.; CONOVER, R. In vitro propagation of papaya. HortScience, Alexandria, v.13, p.241-242, 1978.

LLOYD, G.; McCOWN, B. Commercially-feasible micropropagation of mountain laurel, Kalmia latifolia, by use of shoot-tip culture. Combined Proceedings of International Plant Propagators' Society, Seattle, v.30, p.421-427, 1980.

MACHADO, M.P.; BIASI, L.A.; RITTER, M.; RIBAS, L.L.F.; KOEHLER, H.S.; ZANETTE, F. Meios de cultura na micropropagação do porta-enxerto de videira "VR04343" (Vitis vinifera x Vitis rotundifolia). Ciência Rural, Santa Maria, v.37, n.1, p.277-280, jan./fev. 2007.

MELO, N.F. de; OKASAKI, W.Y.; LEITA, C.B.; FÁRI, M. Estabelecimento do cultivo in vitro da aceroleira (Malpighia emarginata DC.). Ciência e Agrotecnologia, Lavras, v.23, n.1, p.102-107, jan./mar. 1999.

MOLINA, S.M.; SCHOBERT, C. Micropropagation of Ricinus communis. Journal of Plant Physiology, Washington, v.147, p.270-272, June 1995.

MURASHIGE, T.; SKOOG, F. A revised method for rapid growth and bioassays with tobacco tissue cultures.

Physiologia Plantarum, Copenhagen, v.15, p.473-497, 1962.

OLIVEIRA, R.P. de; GOMES, T. da S.; VILARINHOS, A.D. Avaliação de um sistema de micropropagação massal de variedades de mandioca. Pesquisa Agropecuária Brasileira, Brasília, v.35, n.12, p.23292334, dez. 2000.

PERES, E.P.L. Bases fisiológicas e genéticas da regeneração de plantas in vitro. Biotecnologia, Ciência e Desenvolvimento, Brasília, n.25, p.44-48, 2002.

REDDY, K.R.K.; BIR BAHADUR. Adventitious bud formation from leaf cultures of castor (Ricinus communis L.). Current Science, Chicago, v.58, n.3, p.152-154, 1989. 
RIBEIRO, L. de S.; PASQUAL, M.; MACIEL, A.L. de R.; CHAGAS, E.A.; DUTRA, L.F. Multiplicação in vitro de brotações de várias cultivares de Coffea arabica L. em diferentes meios de cultura. Ciência e Agrotecnologia, Lavras, v.26, n.5, p.949-954, set./out. 2002.

SANTOS, A.S.A.; MACHADO, I.S.; LEÃO, A.L.; RAMOS, A.A. Concentrações de BAP e TDZ na propagação in vitro de curauá (Ananas erectifolius L.B. Smith): a influência das citocininas sintéticas na cultura de tecido. Revista de Biotecnologia - Ciência \& Desenvolvimento, Brasília, v.8, n.35, jul./dez. 2005.

SOARES, F.P.; PAIVA, R.; STEIN, V.C.; NERY, F.C.; NOGUEIRA, R.C.; OLIVEIRA, L.M. de. Efeito de meios de cultura, concentrações de $\mathrm{GA}_{3}$ e $\mathrm{pH}$ sobre a germinação in vitro de mangabeira (Hancornia speciosa
Gomes.). Ciência e Agrotecnologia, Lavras, v.33, Edição Especial, p.1847-1852, 2009.

TEIXEIRA, J.B. Limitações ao processo de cultivo in vitro de espécies lenhosas. Brasília: Embrapa-Recursos Genéticos e Biotecnologia, 2001.

TORRES, A.C.; FERREIRA, A.T.; SÁ, F.G. de; BUSO, J.A.; CALDAS, L.S.; NASCIMENTO, A.S.; BRÍGIDO, M. de M.; ROMANO, E. Glossário de biotecnologia vegetal. Brasília: Embrapa Hortaliças, 2000. 128p.

TORRES, A.C.; TEIXEIRA, S.L.; POZZER, L. Cultura de ápices caulinares e recuperação de plantas livres de vírus. In: TORRES, A.C.; CALDAS, L.S.; BUSO, J.A. (Eds.). Cultura de tecidos e transformação genética de plantas. Brasília: Embrapa-SPI/Embrapa-CNPH, 1998. v.2. 